\title{
Online Estimation of the Adhesion Coefficient and Its Derivative Based on the Cascading SMC Observer
}

\author{
Changfan Zhang, ${ }^{1}$ Jian Sun, ${ }^{1}$ Jing He, ${ }^{1,2}$ and Linfan Liu ${ }^{1}$ \\ ${ }^{1}$ Hunan University of Technology, Zhuzhou 412007, China \\ ${ }^{2}$ National University of Defense Technology, Changsha 410073, China \\ Correspondence should be addressed to Jing He; hejing@263.net
}

Received 17 September 2016; Revised 14 November 2016; Accepted 27 November 2016; Published 3 January 2017

Academic Editor: Rene Romero-Troncoso

Copyright (c) 2017 Changfan Zhang et al. This is an open access article distributed under the Creative Commons Attribution License, which permits unrestricted use, distribution, and reproduction in any medium, provided the original work is properly cited.

\begin{abstract}
The adhesion coefficient of wheel-rail surface cannot be directly measured, so a cascaded sliding-mode observer is proposed to observe adhesion coefficient and its derivative. A kinetic model for running heavy-duty locomotive is also established. The state equation of wheel adhesion control system is derived from the equation of traction motor torque balance, and adhesion coefficient is proposed to be calculated by load torque. Then, the cascaded sliding-mode observer is designed, and its stability is justified by Lyapunov stability. Based on the equivalence control principle for sliding-mode variable structure, an algorithm to estimate adhesion coefficient and its derivative is established. The simulation and experimental results are used to verify the effectiveness of the observer with load variations or wheel-rail status changes.
\end{abstract}

\section{Introduction}

Traction power of heavy-duty locomotives has improved along with the rapid development of railway transportation industry. However, the traction power of locomotives is limited by wheel-rail adhesion. The actual value of locomotive wheel-rail adhesion depends on the utilization of locomotive adhesion, which is generally expressed by adhesion coefficient. The wheel-rail adhesion is highly nonlinear and varies rapidly with time because of changes in rails and creep speed. Moreover, the adhesion coefficient cannot be measured directly [1-3]. Smart sensors are a crucial part of automatic detection and control owing to their functions of supervision and diagnosis. High measuring accuracy, quick response, working stability, and data analysis and state judgment functions are all required for sensors to guarantee safety and reliability of locomotives in motion [4]. Therefore, a smart sensor is necessary to supervise and diagnose the adhesion coefficient to maintain optimal adhesion.

Adhesive control algorithms can be divided into two types according to the maximum adhesion point tracking: readhesion control and optimized adhesion control [5].
The readhesion control type [6] adjusts the motor output torque through the driver's handle to restore adhesion after idling, and obtaining a higher adhesion utilization is difficult. Meanwhile, the optimal adhesion control type is mainly the creep speed and the adhesion characteristic curve slope algorithms [7-9]. The creep speed algorithm adjusts the adhesion coefficient repeatedly to maximize the adhesion coefficient, but it requires the measurement of the locomotive speed. Thus, its implementation is difficult. The adhesion characteristic curve slope algorithm is used to let the locomotive work at the peak after obtaining the adhesion characteristic curve in real time. Obtaining the derivative of the adhesion coefficient to the creep speed in this algorithm is difficult. To solve this problem, the adhesive derivative algorithm is proposed to estimate the actual adhesion coefficient and its derivative based on the load torque and its derivative obtained by designing the observer. Takaoka et al. $[10,11]$ and Teramoto et al. [12] proposed observing the load torque with a reduced-dimension observer. The algorithm is simple and can satisfy the basic requirements of the system. However, it is susceptible to noise-signal interference because of its direct differential processing when obtaining the adhesion 


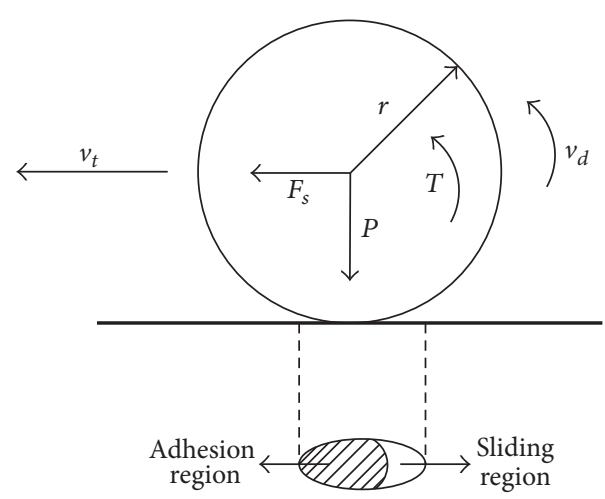

FIgURE 1: Simplified wheel-rail model.

coefficient derivative. Wenli et al. [13] and Liao et al. [14] introduced an omnidirectional observer for the motor load torque and its derivative, thereby improving the system's immunity. The algorithm is based on the assumption that the traction motor load torque does not change. However, ensuring that the motor load torque remains constant with changes in track condition, creep speed, and so on during the actual running of the locomotive is difficult.

The variable structure sliding-mode control (SMC) is robust in the presence of model uncertainties, parameter variations, or external disturbances. The SMC can effectively reduce the dependence on any accurate system model, and its application in the field of state observers has widened [15-17]. This study aims to develop a smart sensor based on the cascaded sliding-mode observer to handle the complex working conditions of locomotive. The sensor determines the load torque and its derivative and then estimates the adhesion coefficient and its derivative.

This paper is structured as follows: the second part describes the wheel-rail kinetic model in the locomotive running process. The third part presents the cascading SMC observer designed to observe the adhesion coefficient and its derivative. The fourth part introduces the simulation analysis. The fifth part provides the conclusions.

\section{Description of the Wheel-Rail System}

The wheels roll forward under the action of driving torque $T$ when the train is running. The wheels relative to the tracks produce creep as a result of elastic deformation on the wheelrail contact surface. They also form an adhesive force on the contact surface, which is the only power for driving the wheels forward, when rolling. Figure 1 shows the simplified uniaxial wheel-rail model.

The creep speed is defined as follows [18]:

$$
v_{s}=v_{d}-v_{t}
$$

Obtaining the locomotive speed $v_{t}$ more accurately is hard.

The adhesion coefficient is defined as follows [19]:

$$
\mu\left(v_{s}\right)=\frac{F_{s}}{W g} .
$$

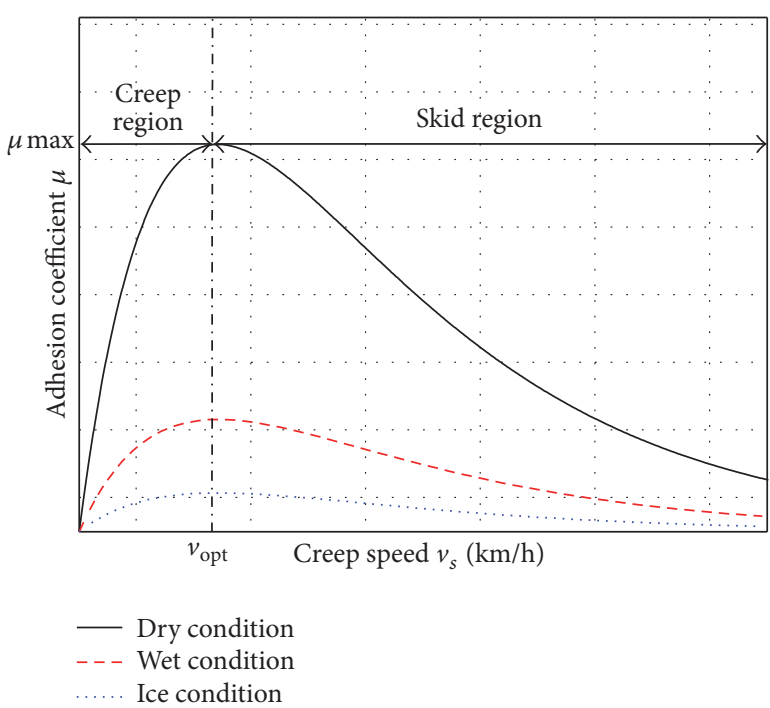

Figure 2: Characteristic curve of the adhesion.

The pulling motor motion equation is as follows [20]:

$$
\begin{aligned}
J_{m} \frac{d \omega_{m}}{d t} & =T_{m}-T_{L}, \\
T_{L} & =\frac{F_{s} r}{R_{g}} .
\end{aligned}
$$

The kinetic equation of the wheel set is

$$
\begin{aligned}
T & =T_{m} R_{g}, \\
F_{t} & =\frac{T}{r}, \\
M_{j} \frac{d v_{d}}{d t} & =F_{t}-F_{s}, \\
M_{j} & =\frac{J}{r^{2}} .
\end{aligned}
$$

The train motion equation is presented as follows:

$$
M \frac{d v_{t}}{d t}=F_{s}-F_{d}\left(v_{t}\right)
$$

where $v_{d}$ is the wheel speed, $F_{s}$ is the adhesion traction, $F_{t}$ is the wheel-rail driving force, $M$ is the locomotive mass, $\mathrm{Wg}$ is the axle load, $J_{m}$ is the equivalent moment of the motor inertia, $J$ is the moment of inertia of the wheel set, $T_{m}$ is the electromagnetic torque of the motor, $T_{L}$ is the motor load torque, $T$ is the driving torque, $r$ is the wheel set radius, $R_{g}$ is the gearbox ratio, and $F_{d}\left(v_{t}\right)$ is the drag.

Figure 2 shows an adhesion characteristic curve, which indicates that the creep speed increases with the traction when the train is running in the creep region. The adhesion coefficient also increases until a peak is reached. The train traction enters a nonstable section when the train traction required exceeds the maximum adhesion force of the wheelrail. The adhesion coefficient within the section sharply 
decreases with higher creep speed. Moreover, the adhesion force of the wheel also reduces, hence the train idling. Locomotive is prone to wheel set idling at two transitions: (1) locomotive suddenly travels from dry high-adhesion railwheel surface to low-adhesion rail-wheel surface and (2) driver pulls up the control handle of locomotive, causing the traction beyond maximum available traction.

The peak point of the adhesion in the locomotive traction process is $d \mu / d v_{s}=0$, with the stable section $d \mu / d v_{s}>0$ on the left side and the idling section $d \mu / d v_{s}<0$ on the right side (Figure 2).

Equation (8) is derived from (7):

$$
\begin{aligned}
& \frac{d \mu}{d v_{s}}=\frac{d \mu / d t}{d v_{s} / d t} \\
& \frac{d \mu}{d v_{s}}=0 \Longrightarrow \frac{d \mu}{d t}=0
\end{aligned}
$$

Using (8), $d \mu / d t$ and $d \mu / d v_{s}$ are equivalent.

Based on the following:

$$
\mu=\frac{R_{g}}{W g r} T_{L}
$$

the load torque $T_{L}$ can be estimated as follows to determine the peak point of the adhesion coefficient.

Using (9),

$$
\dot{\mu}=\frac{R_{g}}{W g r} \dot{T}_{L} .
$$

By selecting the state variables, $x_{1}=\theta, x_{2}=\omega$, and $x_{3}=$ $T_{L}$, where $\theta$ is the displacement angle of the motor and $\omega$ is the motor speed, $\dot{T}_{L}$ is assumed as a bounded variable. Among them, only $x_{1}$ is measurable. The following state equation can be obtained as follows using (3):

$$
\begin{aligned}
& \dot{x}_{1}=x_{2}, \\
& \dot{x}_{2}=-\frac{1}{J_{m}} x_{3}+\frac{1}{J_{m}} T_{m}, \\
& \dot{x}_{3}=\dot{T}_{L}, \\
& y=x_{1} .
\end{aligned}
$$

In literature $[9,10]$, the following state equation is often obtained based on the hypothesis that the rate of change in the motor load torque is 0 :

$$
\begin{aligned}
& \dot{\omega}_{m}=-\frac{1}{J_{m}} T_{L}+\frac{1}{J_{m}} T_{m}, \\
& \dot{T}_{L}=0 .
\end{aligned}
$$

However, in actual locomotive run, change rate in motor load torque being zero is difficult to ensure.

\section{Observer Design}

3.1. Design of Load Torque Observer. As for object $\dot{T}_{L} \neq 0$ described in formula (11), only $x_{1}$ is measurable, and load torque is observed using a cascaded sliding-mode observer as follows:

$$
\begin{aligned}
& \dot{\hat{x}}_{1}=\widehat{x}_{2}+v_{1}, \\
& \dot{\hat{x}}_{2}=\frac{1}{J_{m}} T_{m}+v_{2}, \\
& \widehat{y}=\widehat{x}_{1} .
\end{aligned}
$$

The SMC item is as follows:

$$
\begin{aligned}
& v_{1}=k_{1} \operatorname{sgn}\left(x_{1}-\hat{x}_{1}\right), \\
& v_{2}=k_{2} \operatorname{sgn}\left(x_{2}-\widehat{x}_{2}\right),
\end{aligned}
$$

where $\widehat{x}_{1}, \hat{x}_{2}$ are the observed values of $x_{1}$ and $x_{2}, k_{1}, k_{2}$ are constants to be determined, and $\operatorname{sgn}(\cdot)$ is a sign function.

One defines the observer bias:

$$
\begin{aligned}
& e_{1}=x_{1}-\hat{x}_{1}, \\
& e_{2}=x_{2}-\hat{x}_{2},
\end{aligned}
$$

where $e_{1}$ can be obtained from $x_{1}$ and $\widehat{x}_{1}$. And because $x_{2}$ is unknown, therefore, $e_{2}$ can not be directly obtained.

The following bias equation can be obtained using (11) and (14) as follows:

$$
\begin{aligned}
\dot{e}_{1} & =\dot{x}_{1}-\dot{\hat{x}}_{1}=x_{2}-\left(\widehat{x}_{2}+v_{1}\right)=e_{2}-k_{1} \operatorname{sgn} e_{1}, \\
\dot{e}_{2} & =\dot{x}_{2}-\dot{\hat{x}}_{2}=-\frac{1}{J_{m}} x_{3}+\frac{1}{J_{m}} T_{m}-\left(\frac{1}{J_{m}} T_{m}+v_{2}\right) \\
& =-\frac{1}{J_{m}} x_{3}-k_{2} \operatorname{sgn} e_{2} .
\end{aligned}
$$

Proposition 1. Consider system (11) and its observer (14). For any initial $x_{0} \in R^{n}$, if $k_{i}(i=1,2,3)$ are sufficiently large, the estimated load torque can be calculated by $\widehat{T}_{L}=-J_{m} k_{2}$ sgn $e_{2}$.

Proof.

Step 1. Selecting the Lyapunov function $V_{1}=(1 / 2) e_{1}{ }^{2}$ and considering (18), the derivative of time is

$$
\begin{aligned}
\dot{V}_{1} & =e_{1} \dot{e}_{1}=e_{1}\left(e_{2}-k_{1} \operatorname{sgn} e_{1}\right)=e_{1} e_{2}-k_{1}\left|e_{1}\right| \\
& \leq\left|e_{1}\right|\left|e_{2}\right|-k_{1}\left|e_{1}\right|=\left|e_{1}\right|\left(\left|e_{2}\right|-k_{1}\right) .
\end{aligned}
$$

When $k_{1}$ is large enough,

$$
k_{1} \geq\left|e_{2}\right|+\eta_{1}
$$

and $\eta_{1}$ is an arbitrary positive constant. Then,

$$
\dot{V}_{1}=e_{1} \dot{e}_{1} \leq-\eta_{1}\left|e_{1}\right| \text {. }
$$

The system meets the conditions for the SMC. Accordingly, the system will reach the SMC plane within a limited 
time. After reaching the SMC plane and based on the principle of equivalence of the SMC [21],

$$
e_{1}=\dot{e}_{1}=0 \text {. }
$$

Using (18),

$$
e_{2}=k_{1} \operatorname{sgn} e_{1} .
$$

Step 2. In selecting the Lyapunov function $V_{2}=(1 / 2) e_{2}{ }^{2}+V_{1}$, the derivative of time is obtained as follows:

$$
\dot{V}_{2}=\dot{V}_{1}+e_{2} \dot{e}_{2}
$$

Using (19) and (22),

$$
\begin{aligned}
\dot{V}_{2} & \leq e_{2} \dot{e}_{2}=e_{2}\left(-\frac{1}{J_{m}} x_{3}-k_{2} \operatorname{sgn} e_{2}\right) \\
& =-\frac{1}{J_{m}} e_{2} x_{3}-k_{2}\left|e_{2}\right| \leq \frac{1}{J_{m}}\left|e_{2}\right|\left|x_{3}\right|-k_{2}\left|e_{2}\right| \\
& =\left|e_{2}\right|\left(\frac{1}{J_{m}}\left|x_{3}\right|-k_{2}\right) .
\end{aligned}
$$

When $k_{2}$ is large enough,

$$
k_{2} \geq \frac{1}{J_{m}}\left|x_{3}\right|+\eta_{2}
$$

and $\eta_{2}$ is an arbitrary positive constant; then,

$$
\dot{V}_{2} \leq e_{2} \dot{e}_{2} \leq-\eta_{2}\left|e_{2}\right| \text {. }
$$

Likewise, the following is derived using (19):

$$
\widehat{x}_{3}=-J_{m} k_{2} \operatorname{sgn} e_{2},
$$

where $e_{2}$ is derived from (24).

This completes the proof.

3.2. Design of Load Torque Derivative Observer. As for object $\dot{T}_{L} \neq 0$ described in formula (11), only $x_{1}$ is measurable, and load torque derivative is observed using a cascaded slidingmode observer as follows:

$$
\begin{aligned}
& \dot{\vec{z}}_{1}=\widehat{z}_{2}+v_{3}, \\
& \dot{\vec{z}}_{2}=-\frac{1}{J_{m}} \widehat{z}_{3}+\frac{1}{J_{m}} T_{m}+v_{4}, \\
& \dot{\vec{z}}_{3}=v_{5}, \\
& \hat{y}=\widehat{z}_{1} .
\end{aligned}
$$

The SMC item is as follows:

$$
\begin{aligned}
& v_{3}=\kappa_{1} \operatorname{sgn}\left(x_{1}-\widehat{z}_{1}\right), \\
& v_{4}=\kappa_{2} \operatorname{sgn}\left(x_{2}-\widehat{z}_{2}\right), \\
& v_{5}=\kappa_{3} \operatorname{sgn}\left(x_{3}-\widehat{z}_{3}\right) .
\end{aligned}
$$

where $\widehat{z}_{1}, \widehat{z}_{2}$, and $\widehat{z}_{3}$ are the observed values of $x_{1}, x_{2}$, and $x_{3}$. Meanwhile, $\kappa_{1}, \kappa_{2}$, and $\kappa_{3}$ are constants to be determined, and $\operatorname{sgn}(\cdot)$ is a sign function.
The state estimation error is defined as

$$
\begin{aligned}
& E_{1}=x_{1}-\widehat{z}_{1}, \\
& E_{2}=x_{2}-\widehat{z}_{2}, \\
& E_{3}=x_{3}-\widehat{z}_{3},
\end{aligned}
$$

where $E_{1}$ can be obtained from $x_{1}$ and $\widehat{z}_{1}$. And because $x_{2}$ and $x_{3}$ are unknown, therefore, $E_{2}$ and $E_{3}$ can not be directly obtained.

The following bias equation can be obtained using (11) and (30) as follows:

$$
\begin{aligned}
\dot{E}_{1} & =\dot{x}_{1}-\dot{\vec{z}}_{1}=x_{2}-\left(\widehat{z}_{2}+v_{3}\right)=E_{2}-\kappa_{1} \operatorname{sgn} E_{1}, \\
\dot{E}_{2} & =\dot{x}_{2}-\dot{\vec{z}}_{2} \\
& =-\frac{1}{J_{m}} x_{3}+\frac{1}{J_{m}} T_{m}-\left(-\frac{1}{J_{m}} \widehat{z}_{3}+\frac{1}{J_{m}} T_{m}+v_{4}\right) \\
& =-\frac{1}{J_{m}} E_{3}-\kappa_{2} \operatorname{sgn} E_{2}, \\
\dot{E}_{3} & =\dot{x}_{3}-\dot{\hat{z}}_{3}=\dot{T}_{L}-v_{5}=\dot{T}_{L}-\kappa_{3} \operatorname{sgn} E_{3} .
\end{aligned}
$$

Proposition 2. Consider system (11) and its observer (30) or any initial $x_{0} \in R^{n}$, and if $\kappa_{i}(i=1,2,3)$ are sufficiently large, the estimated load torque derivative can be calculated by $\widehat{\dot{T}}_{L}=$ $\kappa_{3} \operatorname{sgn} E_{3}$.

Proof.

Step 1. Selecting the Lyapunov function $V_{3}=(1 / 2) E_{1}{ }^{2}$ and considering (36), the derivative of time is

$$
\begin{aligned}
\dot{V}_{3} & =E_{1} \dot{E}_{1}=E_{1}\left(E_{2}-\kappa_{1} \operatorname{sgn} E_{1}\right)=E_{1} E_{2}-\kappa_{1}\left|E_{1}\right| \\
& \leq\left|E_{1}\right|\left|E_{2}\right|-\kappa_{1}\left|E_{1}\right|=\left|E_{1}\right|\left(\left|E_{2}\right|-\kappa_{1}\right) .
\end{aligned}
$$

When $\kappa_{1}$ is large enough,

$$
\kappa_{1} \geq\left|E_{2}\right|+\delta_{1}
$$

and $\delta_{1}$ is an arbitrary positive constant. Then,

$$
\dot{V}_{3}=E_{1} \dot{E}_{1} \leq-\delta_{1}\left|E_{1}\right| \text {. }
$$

The system meets the conditions for the SMC. Accordingly, the system will reach the SMC plane within a limited time. After reaching the SMC plane and based on the principle of equivalence of the SMC [21],

$$
E_{1}=\dot{E}_{1}=0
$$

Using (36),

$$
E_{2}=\kappa_{1} \operatorname{sgn} E_{1}
$$

Step 2. In selecting the Lyapunov function $V_{4}=(1 / 2) E_{2}{ }^{2}+V_{3}$, the derivative of time is obtained as follows:

$$
\dot{V}_{4}=\dot{V}_{3}+E_{2} \dot{E}_{2} \text {. }
$$




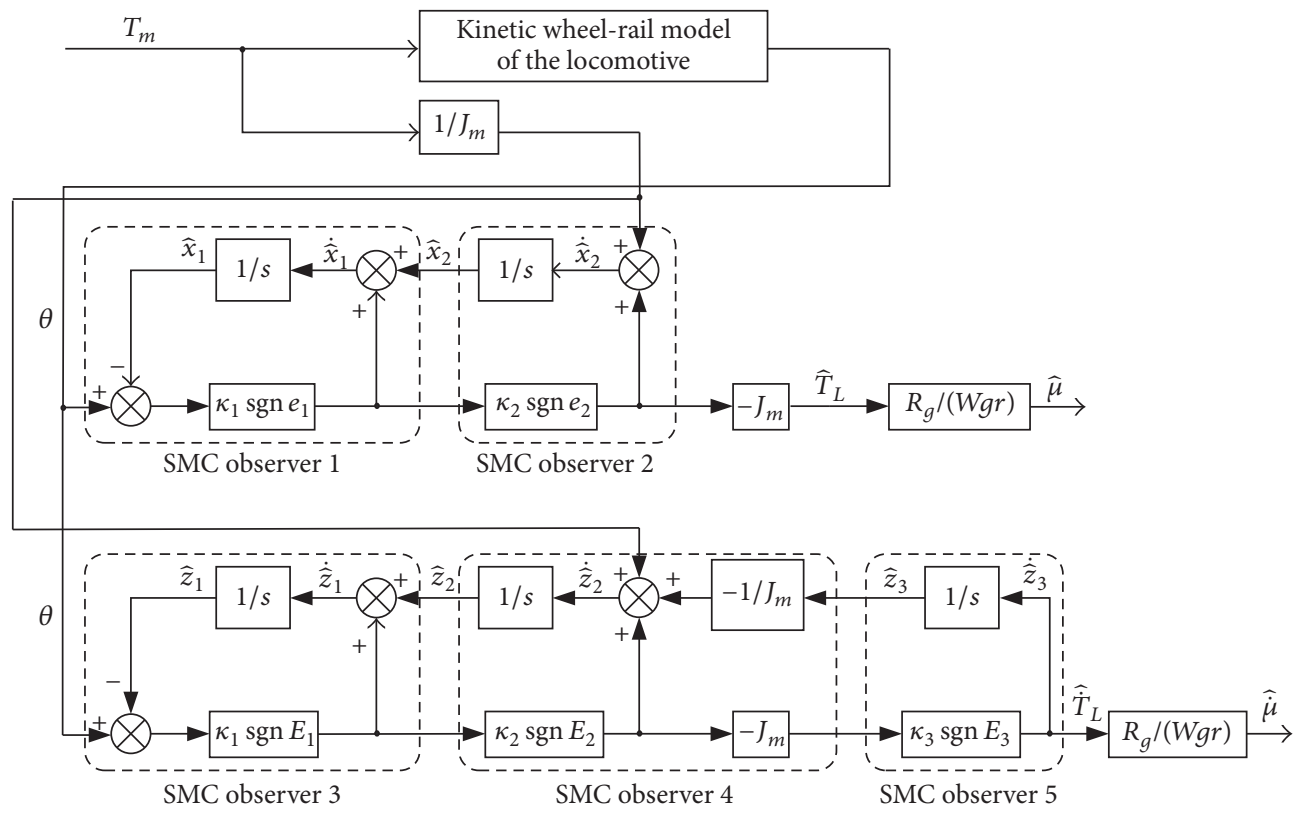

FIGURE 3: System diagram of the derivative observer of the adhesion coefficient.

Using (37) and (41),

$$
\begin{aligned}
\dot{V}_{4} & \leq E_{2} \dot{E}_{2}=E_{2}\left(-\frac{1}{J_{m}} E_{3}-\kappa_{2} \operatorname{sgn} E_{2}\right) \\
& =-\frac{1}{J_{m}} E_{2} E_{3}-\kappa_{2}\left|E_{2}\right| \leq \frac{1}{J_{m}}\left|E_{2}\right|\left|E_{3}\right|-\kappa_{2}\left|E_{2}\right| \\
& =\left|E_{2}\right|\left(\frac{1}{J_{m}}\left|E_{3}\right|-\kappa_{2}\right) .
\end{aligned}
$$

When $\kappa_{2}$ is large enough,

$$
\kappa_{2} \geq \frac{1}{J_{m}}\left|E_{3}\right|+\delta_{2}
$$

and $\delta_{2}$ is an arbitrary positive constant; then,

$$
\dot{V}_{4} \leq E_{2} \dot{E}_{2} \leq-\delta_{2}\left|E_{2}\right|
$$

Likewise, the following is derived using (37):

$$
E_{3}=-J_{m} \kappa_{2} \operatorname{sgn} E_{2},
$$

where $E_{2}$ is derived from (43).

Step 3. In selecting the Lyapunov function $V_{5}=(1 / 2) E_{3}{ }^{2}+V_{4}$, the derivative of time is

$$
\dot{V}_{5}=\dot{V}_{4}+E_{3} \dot{E}_{3} .
$$

Using (38) and (47),

$$
\begin{aligned}
\dot{V}_{5} & \leq E_{3} \dot{E}_{3}=E_{3}\left(\dot{T}_{L}-\kappa_{3} \operatorname{sgn} E_{3}\right)=E_{3} \dot{T}_{L}-\kappa_{3}\left|E_{3}\right| \\
& \leq\left|E_{3}\right|\left|\dot{T}_{L}\right|-\kappa_{3}\left|E_{3}\right|=\left|E_{3}\right|\left(\left|\dot{T}_{L}\right|-\kappa_{3}\right) .
\end{aligned}
$$

When $\kappa_{3}$ is large enough,

$$
\kappa_{3} \geq\left|\dot{T}_{L}\right|+\delta_{3}
$$

and $\delta_{3}$ is an arbitrary positive constant; then

$$
\dot{V}_{5} \leq E_{3} \dot{E}_{3} \leq-\delta_{3}\left|E_{3}\right| .
$$

Likewise, the following is obtained using (38):

$$
\widehat{\dot{T}}_{L}=\kappa_{3} \operatorname{sgn} E_{3},
$$

where $E_{3}$ is derived from (48).

This completes the proof.

The SMC-based observer algorithm of the adhesion coefficient and its derivative is summarized as follows:

(1) Load torque observers and its derivative are established by formulas (14) and (30), respectively.

(2) By (24), $e_{2}$ can be estimated.

(3) By (29), $\widehat{T}_{L}$ can be estimated.

(4) By (43), $E_{2}$ can be estimated.

(5) By (48), $E_{3}$ can be estimated.

(6) By (53), $\hat{\dot{T}}_{L}$ can be estimated.

The sign function $\operatorname{sgn}\left(e_{i}\right)$ is replaced with the relay method, $\operatorname{sgn}\left(e_{i}\right)=e_{i} /\left(\left|e_{i}\right|+\delta_{i}\right)$, to solve the chattering problem of the SMC observer. $\delta_{1}$ is a very small positive constant.

(7) By (9) and (10), $u$ and its derivative $\dot{u}$ can be estimated.

Hence, the adhesion coefficient $u$ and its derivative $\dot{u}$ can be obtained, with the corresponding SMC observer structured as Figure 3. 


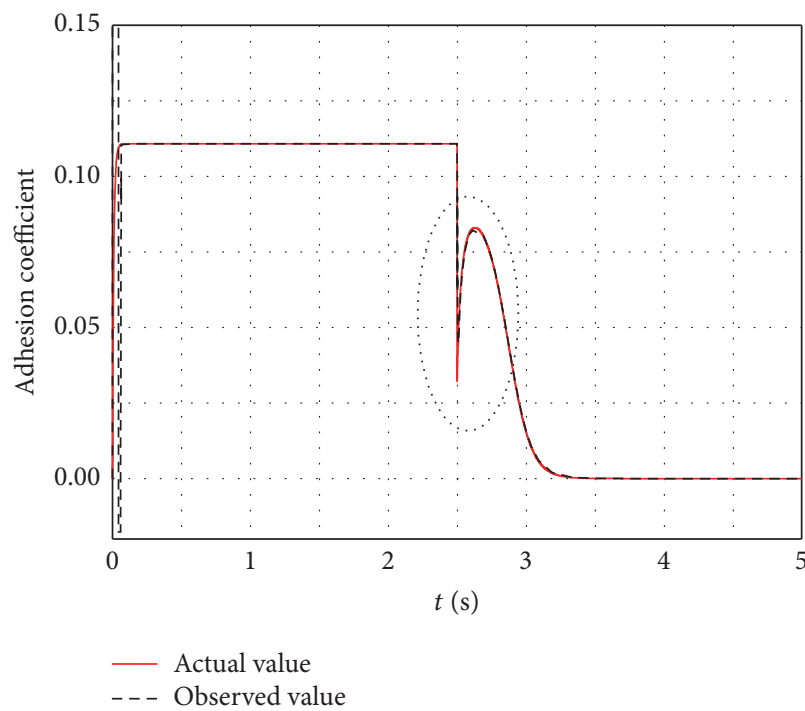

(a) Original image

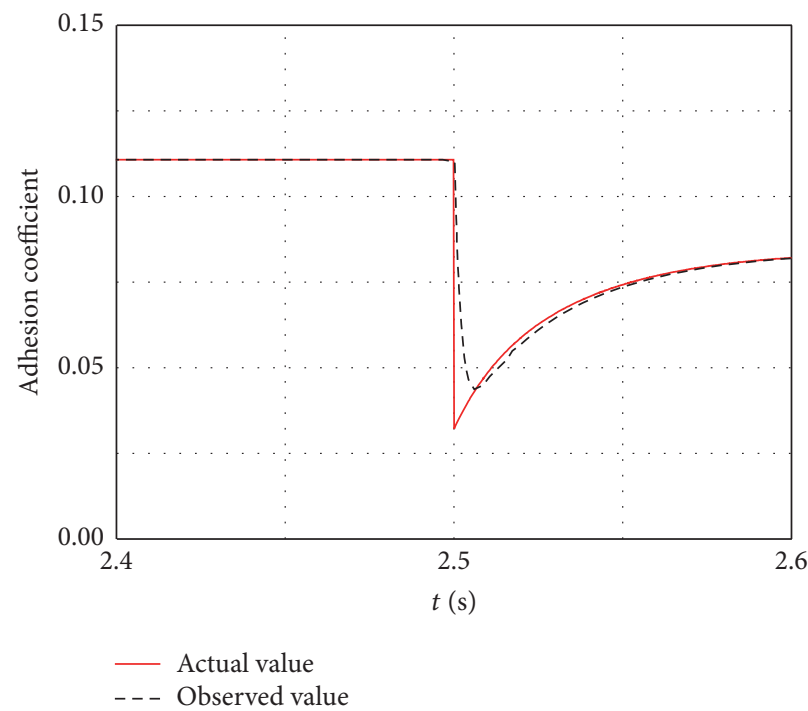

(b) Partially enlarged view

FIGURE 4: Wheel-rail adhesion coefficient.

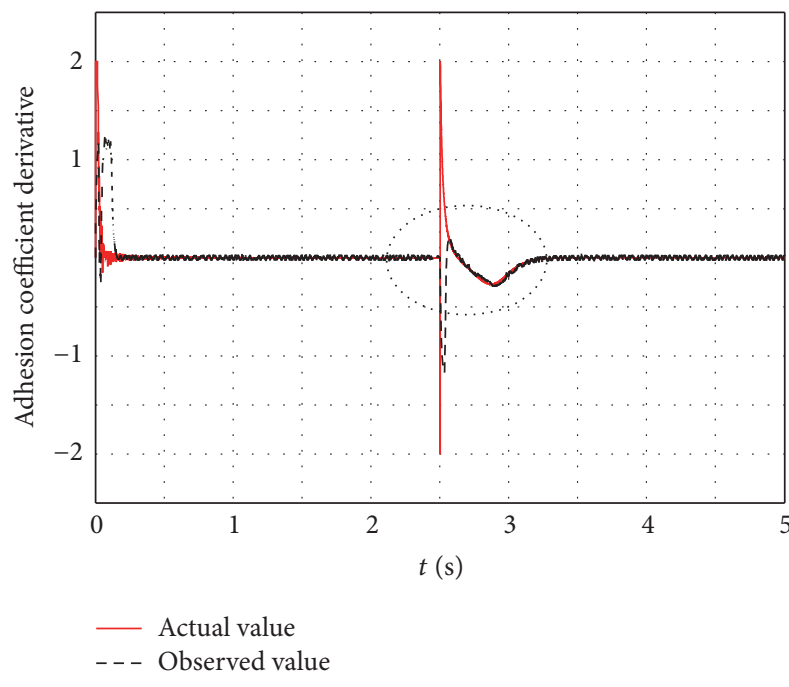

(a) Original image

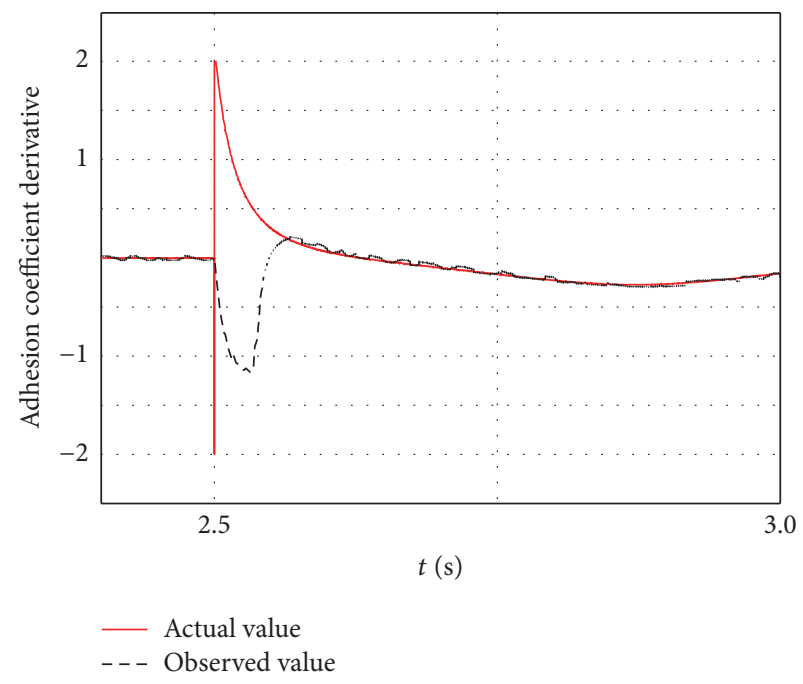

(b) Partially enlarged view

FIGURE 5: Wheel-rail adhesion coefficient derivative.

\section{Simulation and Experiment}

4.1. Simulation Results and Analysis. The adhesion coefficient and its derivative are testified by a uniaxial locomotive simulation model established using MATLAB/Simulink.

Case 1. Simulation environment for locomotive starts with dry track surface, and $T_{m}$ remains $6500 \mathrm{~N} \cdot \mathrm{m}$. Figures 4 and 5 show wheel-rail adhesion coefficient and adhesion coefficient derivative, respectively. In the figures, solid red and black-dotted lines represent actual and observed values, respectively. Figures 6 and 7 show motor angular displacement and speed, respectively. In the figures, solid red, blue-dotted, and black-dotted lines represent actual value, observed value from load torque observer, and observed value from derivative observer, respectively. As shown in Figures 4 and 5, adhesion coefficient immediately increases from zero to 0.11 , and adhesion coefficient derivative is zero. At $2.5 \mathrm{~s}$, locomotive travels from dry to wet rail surface, and wheel-rail adhesion does not meet locomotive traction needs. When the locomotive runs to idling section, adhesion coefficient declines to zero. A majority of solid red line tallies with black-dotted line; and the observed value matches the actual value well. As shown in Figures 6 and 7, when initial observer value is different, values of angular displacement and speed observed from two observers are in line with actual values. 


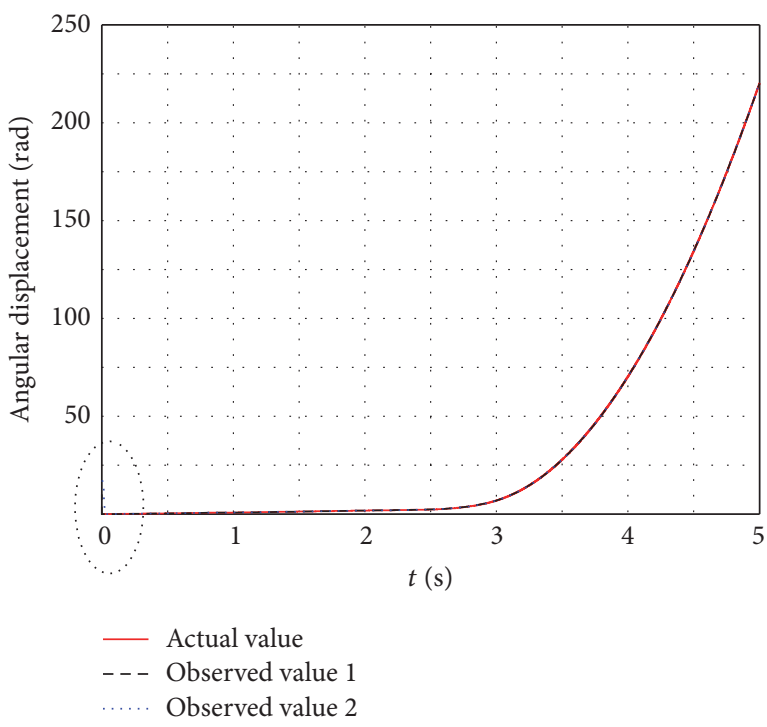

(a) Original image

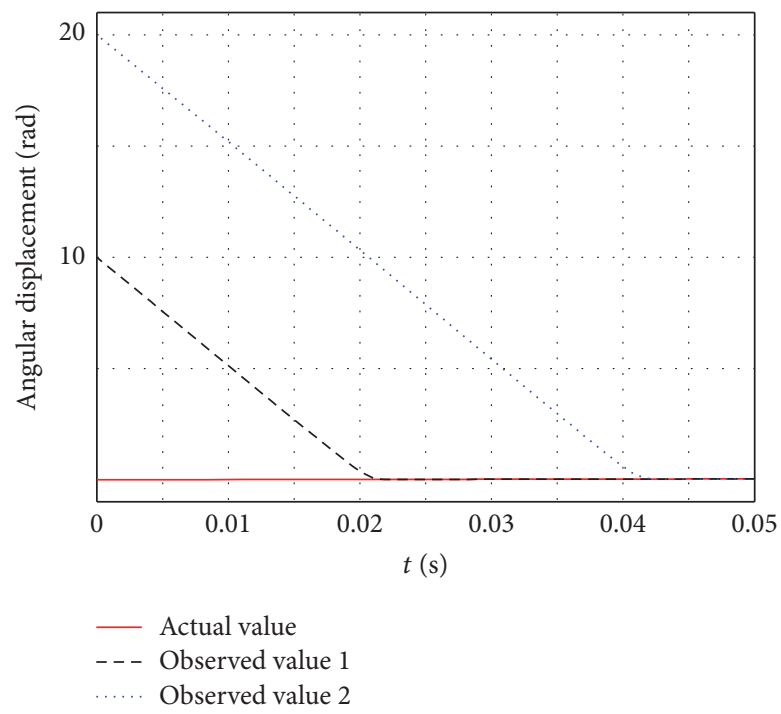

(b) Partially enlarged view

Figure 6: Motor angular displacement.

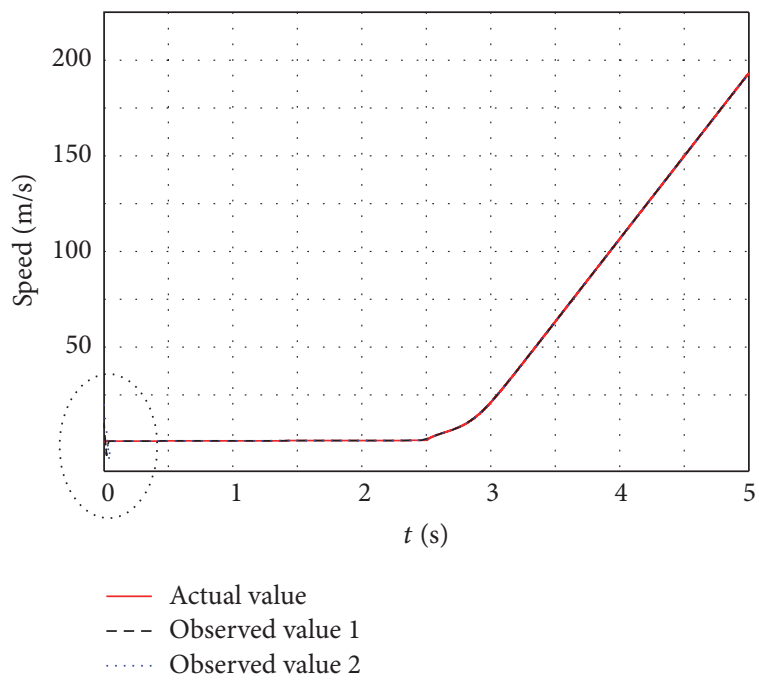

(a) Original image

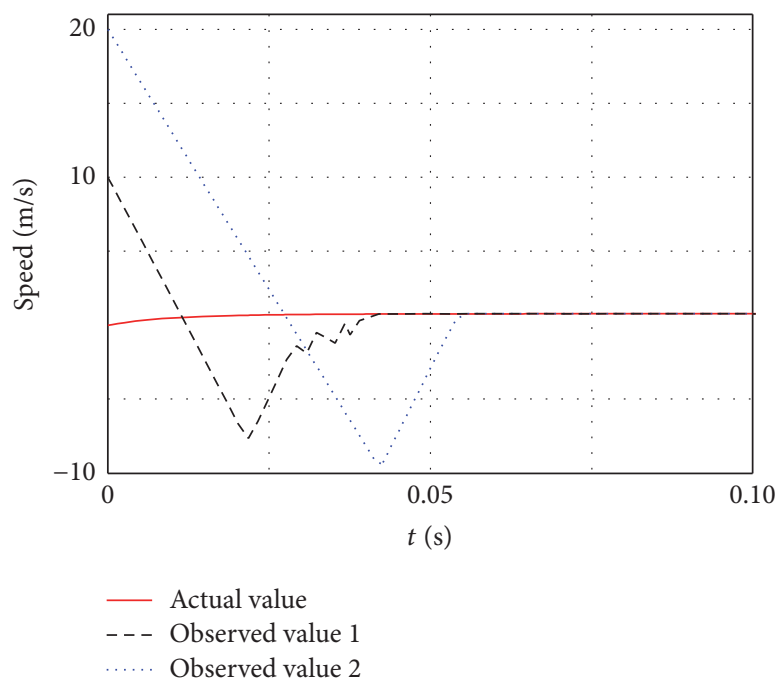

(b) Partially enlarged view

FIGURE 7: Motor speed.

Case 2. Simulation environment for locomotive is always in a dry state, and initial value of $T_{m}$ is zero, with an increase by $2000 \mathrm{~N} \cdot \mathrm{m} / \mathrm{s}$. Figures 8 and 9 show wheel-rail adhesion coefficient and adhesion coefficient derivative, respectively. In the figures, red solid, blue-dotted, and black-dotted lines represent actual value, observed value from load torque observer, and observed value from derivative observer, respectively. As shown in Figures 8 and 9, adhesion coefficient increases proportionally; adhesion coefficient derivative rises rapidly to a constant; and locomotive runs in creep section. Observed value is in line with actual value. As shown in Figures 10 and 11 , observed values of motor angular displacement and speed from observers agree with actual values well, considering the varying initial observer value.

4.2. Experimental Results and Analysis. RT-LAB is a powerful, modular, distributed, real-time platform from OPALRT Technologies, Inc. It supports model-based design using rapid control prototyping (RCP) and hardware-in-the-loop simulation (HILS) of complex dynamic systems. HILS differs from pure real-time simulation and RCP by the use of the real controller in the loop; this controller is connected to the rest of the system simulated by RT-LAB. Therefore, in HILS, the plant is simulated, but the controller is real $[22,23]$. To 


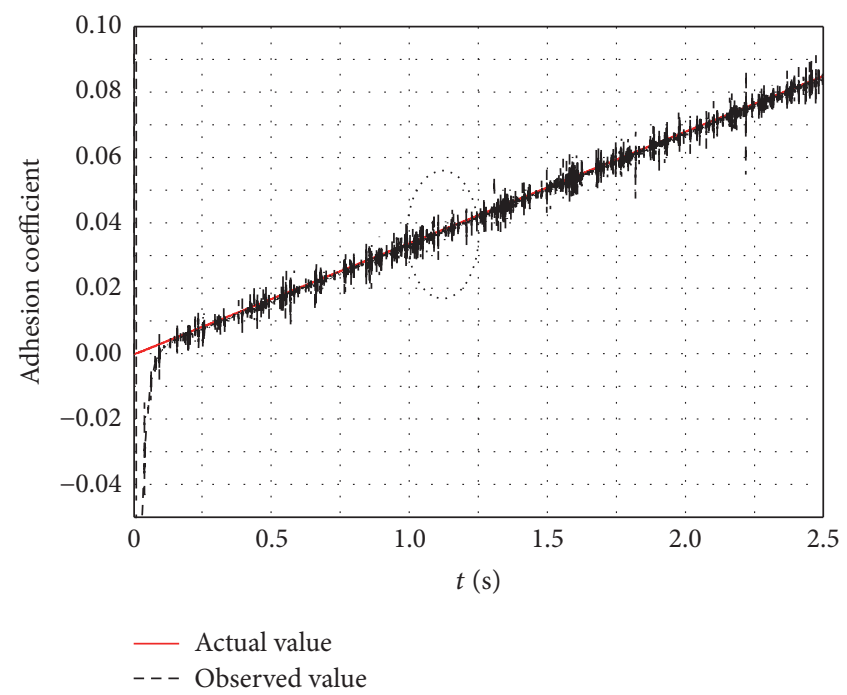

(a) Original image

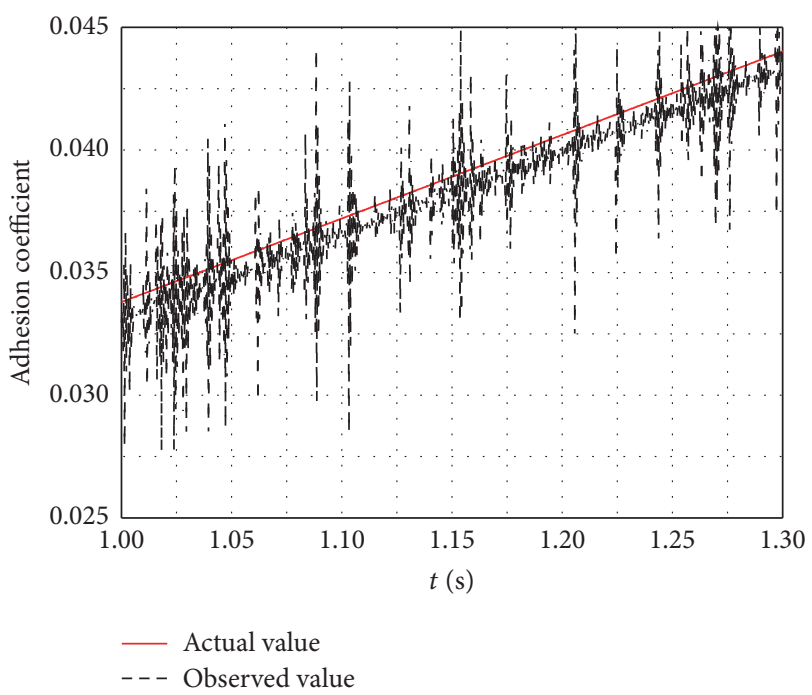

(b) Partially enlarged view

FIGURE 8: Wheel-rail adhesion coefficient.

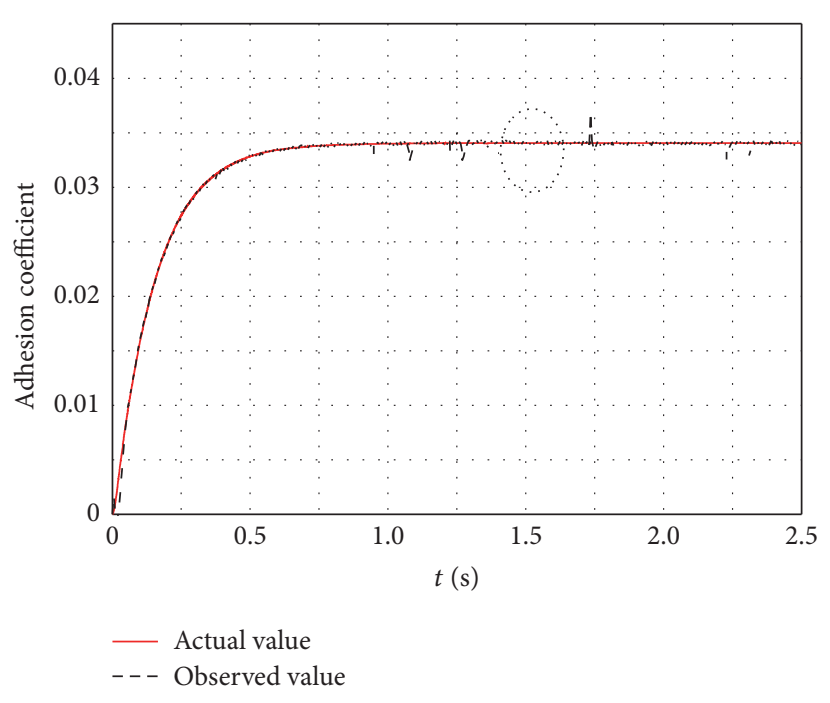

(a) Original image

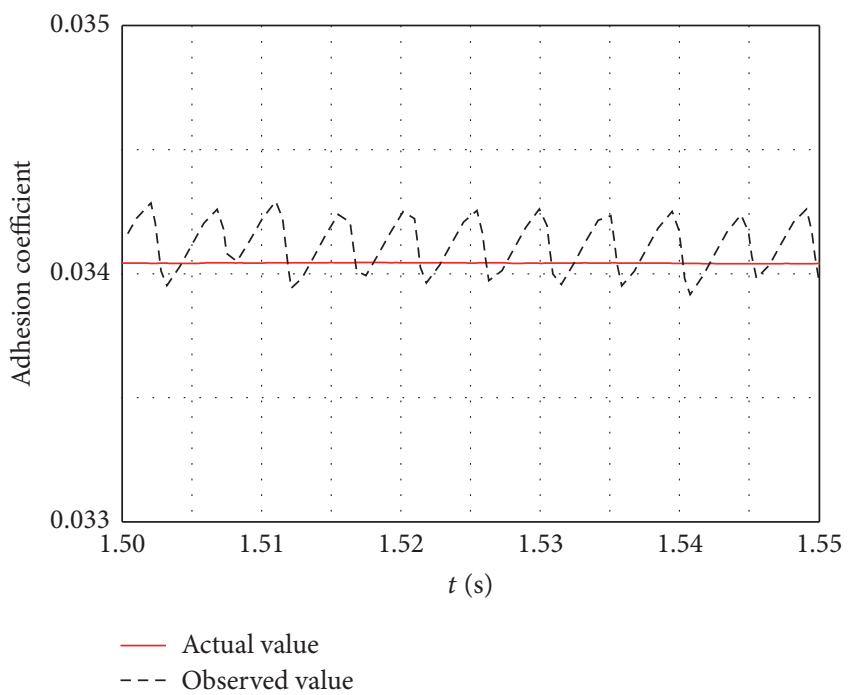

(b) Partially enlarged view

FIGURE 9: Wheel-rail adhesion coefficient derivative.

implement the proposed approach, experiments have been carried out on an OP5600 RT-LAB platform using HILS. The RT-LAB platform is shown in Figure 12, and the configuration is shown in Figure 13. The observer is a TMS320F2812 digital signal processor, which implements high-performance control and computation. The motor and wheel-rail system are simulated by RT-LAB. The sampling period is chosen as $50 \mu \mathrm{s}$, which is the same as the SMO. The semiphysical simulation results are shown in Figures 14-17.

Case 1. Experiment environment for locomotive starts with dry track surface; at $2.5 \mathrm{~s}$, locomotive travels from dry to wet rail surface.
Case 2. Experiment environment for locomotive is always in a dry state, and initial value of $T_{m}$ is zero, with an increase by $2000 \mathrm{~N} \cdot \mathrm{m} / \mathrm{s}$.

Results Analysis. Figures 14 and 15 are the experimental waveforms under the change of the rail surface. In Figure 14, the oscilloscope shows the adhesion coefficient; in Figure 15, the oscilloscope shows the adhesion coefficient derivative, $\mathrm{CH} 3$ channel shows the actual value, and $\mathrm{CH} 1$ channel shows the observed value. The rail surface changes from dry to wet state in $2.5 \mathrm{~s}$, the locomotive running into the skid region. Figures 16 and 17 are experimental waveforms under the change of traction force. In Figure 16, the oscilloscope shows 


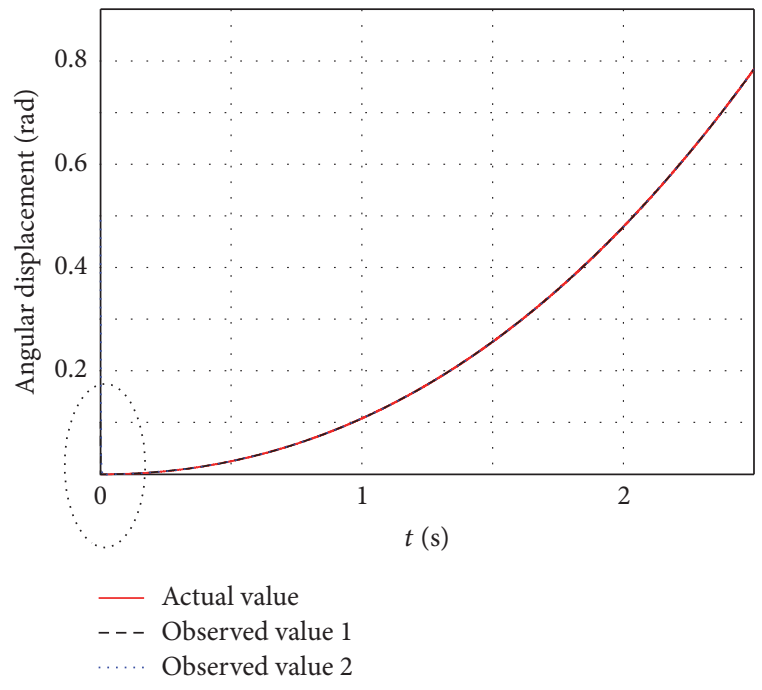

(a) Original image

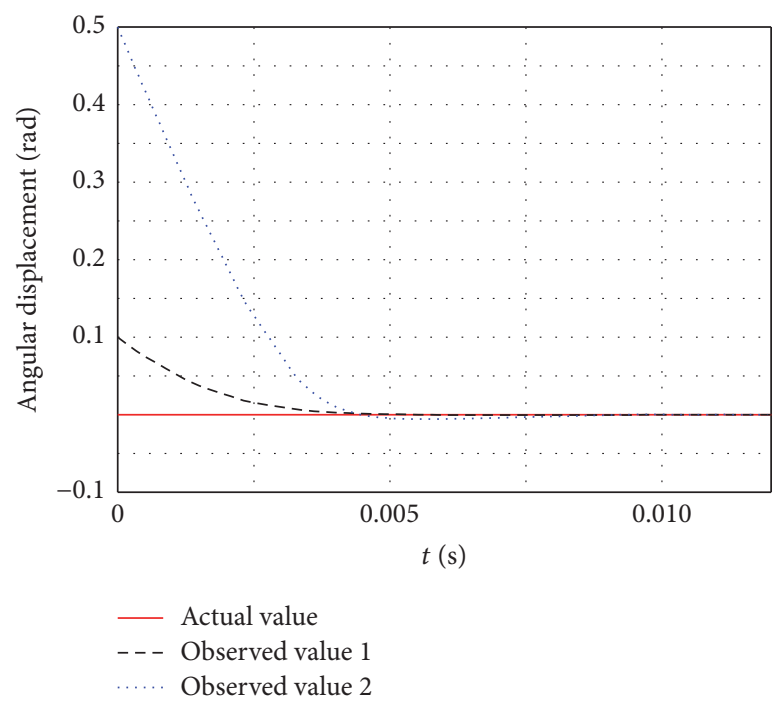

(b) Partially enlarged view

FIGURE 10: Motor angular displacement.

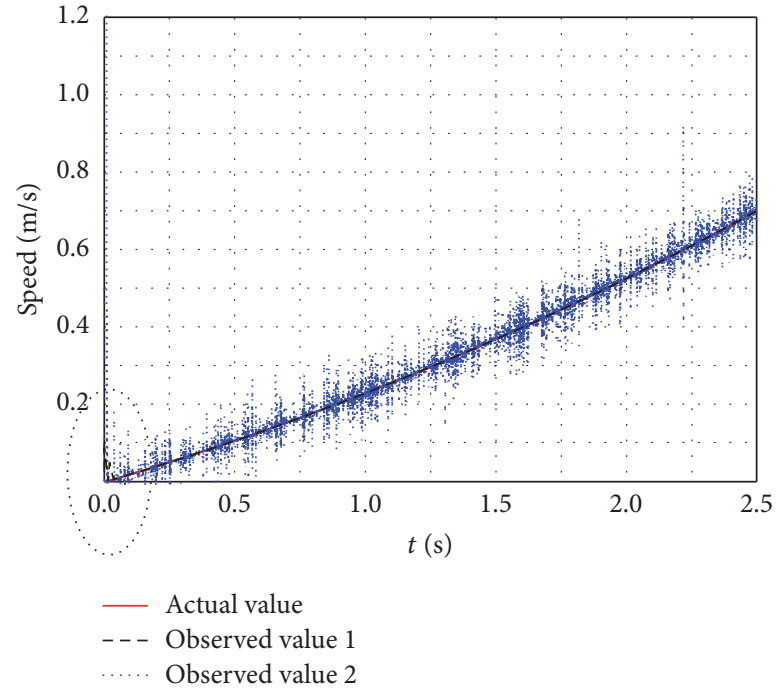

(a) Original image

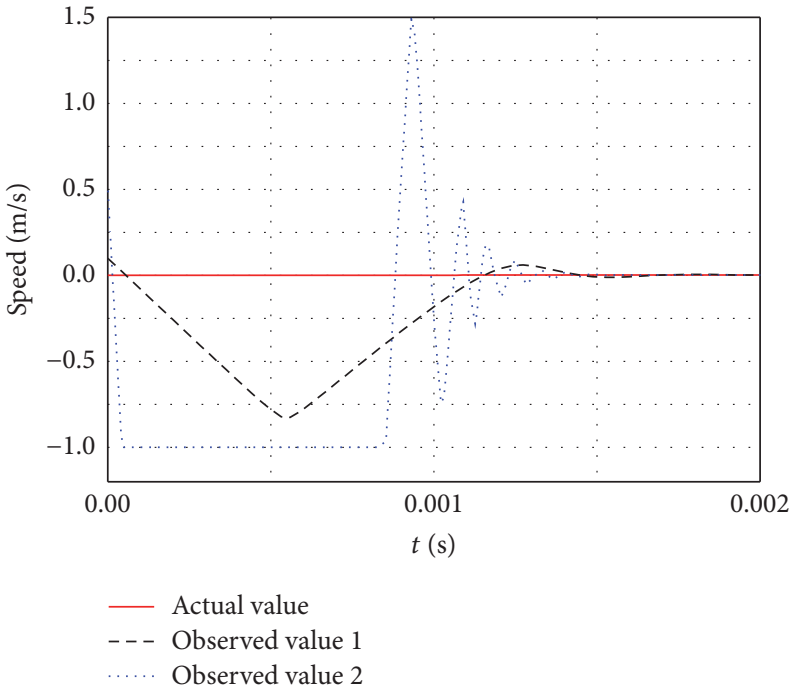

(b) Partially enlarged view

FIGURE 11: Motor speed.

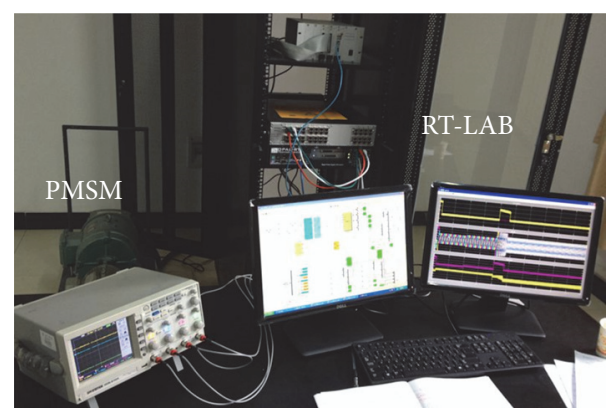

FIGURE 12: RT-LAB experiment setup. the adhesion coefficient; in Figure 17, the oscilloscope shows the adhesion coefficient derivative, $\mathrm{CH} 3$ channel shows the actual value, and $\mathrm{CH} 2$ channel shows the observed value. It can be seen that the adhesion coefficient is increased by the positive proportion, and the locomotive runs in the microslip area. The experimental results are in agreement with the simulation results.

\section{Conclusions}

Obtaining the wheel-rail adhesion state is extremely hard. This study designs a method to estimate the adhesion 


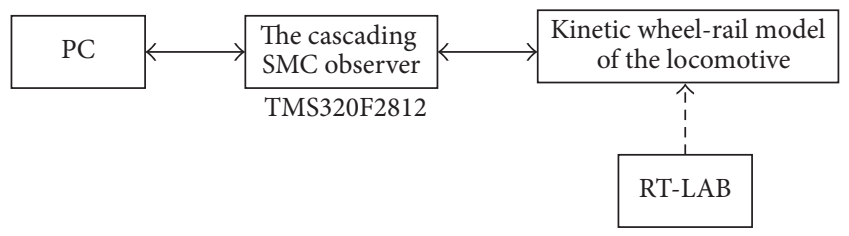

FIGURE 13: The structure of RT-LAB hardware-in-the-loop system.

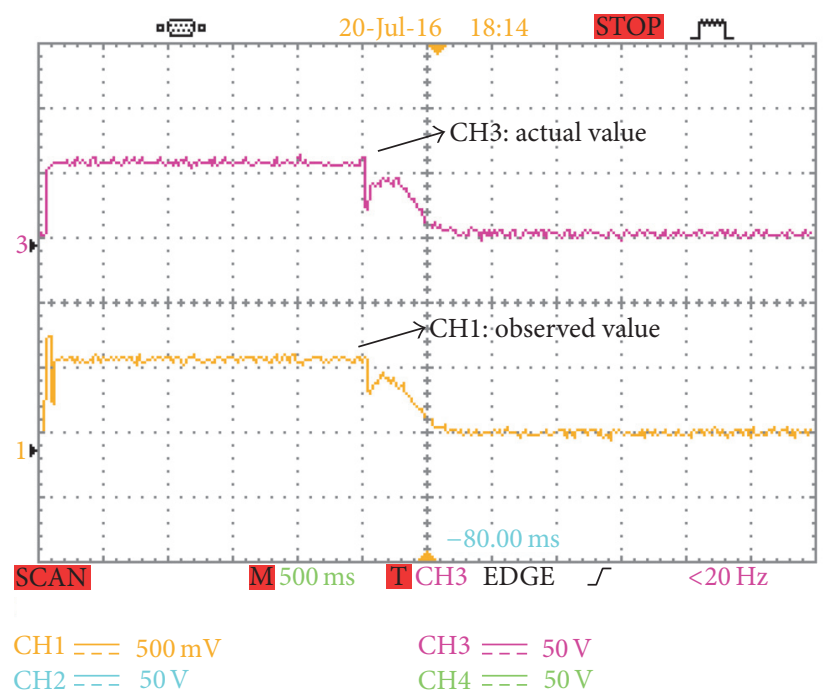

FIGURE 14: Wheel-rail adhesion coefficient. Adhesion coefficient: 0.01/grid; time: 0.5 s/grid.

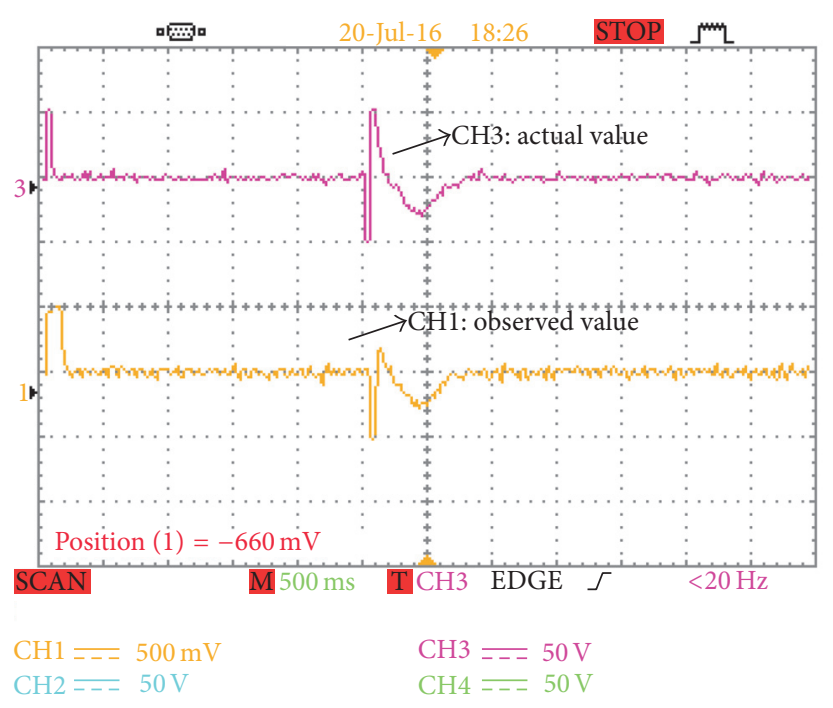

FIGURE 15: Wheel-rail adhesion coefficient derivative. Adhesion coefficient derivative: $0.1 /$ grid; time: $0.5 \mathrm{~s} /$ grid.

coefficient and its derivative online based on the cascading SMC observer. Mathematical model of wheel-rail is obtained by analyzing wheel-rail adhesion mechanism, which is proposed to estimate adhesion coefficient by load torque. The derivative of the torque load in the existing algorithms is required to be 0 ; that is, $\dot{T}_{L}=0$. However, in the practical

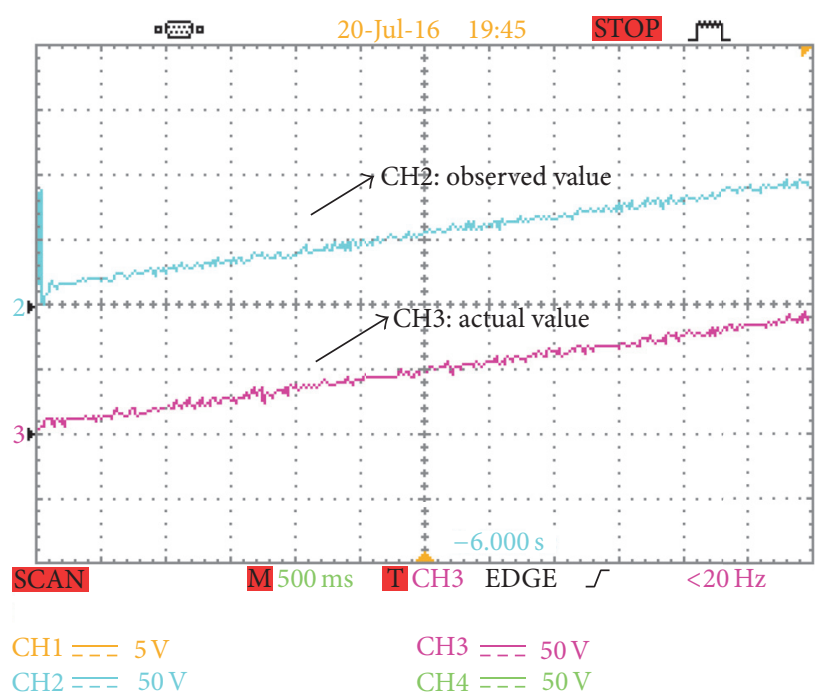

FIGURE 16: Wheel-rail adhesion coefficient. Adhesion coefficient: 0.01/grid; time: 0.5 s/grid.

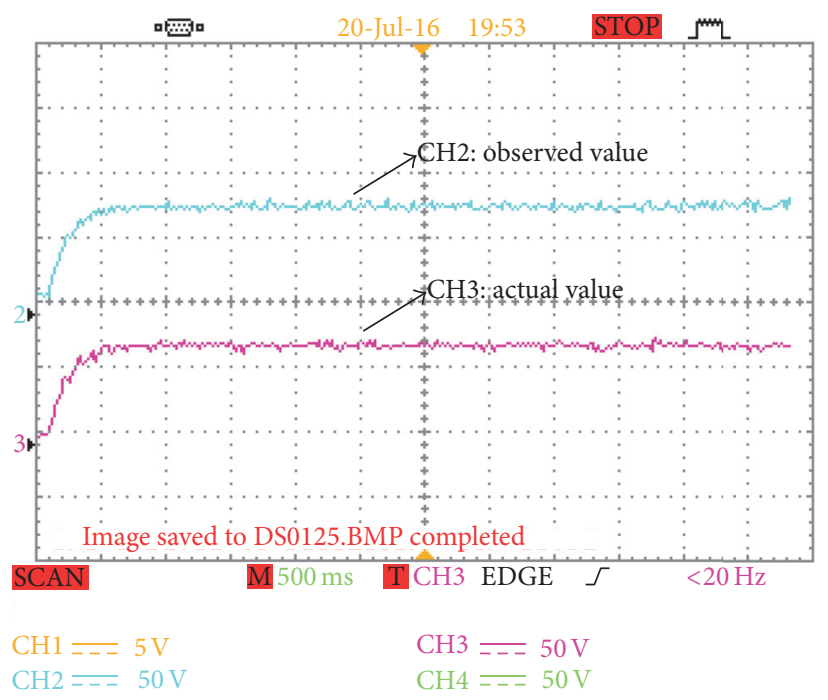

FIGURE 17: Wheel-rail adhesion coefficient derivative. Adhesion coefficient derivative: $0.005 /$ grid; time: 0.5 s/grid.

operation of locomotives, this is difficult to guarantee because of the changing track conditions and creep speed. In the present study, this assumption is relaxed; that is, it should only be assumed as a bounded quantity. The derivative of the load torque is estimated using the principle of equivalence in SMC. The chattering problem of the SMC observer is then solved. The algorithm proposed in this study has a simple structure with high robustness and is easy to implement. By means of simulation and experiment, the observed values are consistent with the actual values, which confirms the algorithm validity

\section{Competing Interests}

The authors declare no conflict of interests. 


\section{Acknowledgments}

This work was supported by the Natural Science Foundation of China (nos. 61273157 and 61473117) and Natural Science Foundation of Hunan Province (2016JJ5007).

\section{References}

[1] K. Xu, G. Xu, and C. Zheng, "Novel determination of WheelRail adhesion stability for electric locomotives," International Journal of Precision Engineering and Manufacturing, vol. 16, no. 4, pp. 653-660, 2015.

[2] Z. Gao, B. Jiang, P. Shi, M. Qian, and J. Lin, "Active fault tolerant control design for reusable launch vehicle using adaptive sliding mode technique," Journal of the Franklin Institute. Engineering and Applied Mathematics, vol. 349, no. 4, pp. 1543-1560, 2012.

[3] M. Spiryagin, K. S. Lee, and H. H. Yoo, "Control system for maximum use of adhesive forces of a railway vehicle in a tractive mode," Mechanical Systems and Signal Processing, vol. 22, no. 3, pp. 709-720, 2008.

[4] I. F. Akyildiz, W. Su, Y. Sankarasubramaniam, and E. Cayirci, "A survey on sensor networks," IEEE Communications Magazine, vol. 40, no. 8, pp. 102-114, 2002.

[5] Y. Tian, S. Liu, W. J. T. Daniel, and P. A. Meehan, "Investigation of the impact of locomotive creep control on wear under changing contact conditions," Vehicle System Dynamics, vol. 53, no. 5, pp. 692-709, 2015.

[6] O. Yamazaki, S. Fukasawa, S. Ohashi, and K. Kondo, "The proposal of re-adhesion control method with the advantage of individual control system," in Proceedings of the International Conference on Electrical Systems for Aircraft, Railway, Ship Propulsion and Road Vehicles (ESARS '15), pp. 1-6, Aachen, Germany, March 2015.

[7] C. Wenchuan, L. Danyong, and L. S. Yongduan, "A novel approach for active adhesion control of high-speed trains under antiskid constraints," IEEE Transactions on Intelligent Transportation Systems, vol. 16, no. 6, pp. 3213-3222, 2015.

[8] W. Yang, W. Cai, and Y. Song, "A barrier Lyapunov function (BLF) based approach for antiskid traction/braking control of high speed trains," in Proceedings of the 26th Chinese Control and Decision Conference (CCDC '14), pp. 5023-5028, Changsha, China, June 2014.

[9] G. Xu, K. Xu, C. Zheng, and T. Zahid, "Optimal operation point detection based on force transmitting behavior for wheel slip prevention of electric vehicles," IEEE Transactions on Intelligent Transportation Systems, vol. 17, no. 2, pp. 481-490, 2016.

[10] Y. Takaoka and A. Kawamura, "Disturbance observer based adhesion control for Shinkansen," in Proceedings of the 6th International Workshop on Advanced Motion Control, pp. 169174, Nagoya, Japan, March-April 2000.

[11] A. Kawamura, K. Takeuchi, T. Furuya, Y. Takaoka, K. Yoshimoto, and M. Cao, "Measurement of the tractive force and the new adhesion control by the newly developed tractive force measurement equipment," in Proceedings of the IEEE Power Conversion Conference, vol. 2, pp. 169-174, Osaka, Japan, April 2002.

[12] K. Teramoto, K. Ohishi, S. Makishima, K. Uezono, and S. Yasukawa, "Cooperative control of regenerative brake and mechanical brake for a two coach train," in Proceedings of the 38th Annual Conference on IEEE Industrial Electronics Society (IECON '12), pp. 1707-1712, IEEE, Montreal, Canada, October 2012.
[13] L. Wenli, Z. Leiting, and D. Kan, "Performance analysis of readhesion optimization control based on full-dimension state observer," Procedia Engineering, vol. 23, pp. 531-536, 2011.

[14] W. Liao, H. Chen, W. Cai, and Y. Song, "A novel active adhesion control design for high speed trains without vehicle speed measurement," in Proceedings of the 33rd Chinese Control Conference (CCC '14), pp. 221-226, Nanjing, China, July 2014.

[15] R. Sharma and M. Aldeen, "Design of integral sliding mode observers with application to fault and unknown input reconstruction," in Proceedings of the 48th IEEE Conference on Decision and Control held jointly with 2009 28th Chinese Control Conference (CDC/CCC '09), pp. 6958-6963, Shanghai, China, December 2009.

[16] J. Yang, S. Li, and X. Yu, "Sliding-mode control for systems with mismatched uncertainties via a disturbance observer," IEEE Transactions on Industrial Electronics, vol. 60, no. 1, pp. 160-169, 2013.

[17] F. Floret-Pontet and F. Lamnabhi-Lagarrigue, "State and parameter identification for nonlinear uncertain systems using variable structure theory," in Nonlinear and Adaptive Control, vol. 281 of Lecture Notes in Control and Information Sciences, pp. 109-128, Springer, Berlin, Germany, 2003.

[18] T. Hara and T. Koseki, "Study on re-adhesion control by monitoring excessive angular momentum in electric railway tractions," in Proceedings of the 12th IEEE International Workshop on Advanced Motion Control (AMC '12), IEEE, March 2012.

[19] N. Patel, C. Edwards, and S. K. Spurgeon, "A sliding mode observer for tyre friction estimation during braking," in Proceedings of the American Control Conference, pp. 5867-5872, Minneapolis, Minn, USA, June 2006.

[20] Y. Shimizu, K. Ohishi, T. Sano, and S. Yasukawa, "Anti-slip/slid re-adhesion control based on disturbance observer considering bogie vibration," Electrical Engineering in Japan, vol. 172, no. 2, pp. 37-46, 2010.

[21] S. K. Spurgeon, "Sliding mode observers: a survey," International Journal of Systems Science, vol. 39, no. 8, pp. 751-764, 2008.

[22] K.-H. Zhao, T.-F. Chen, C.-F. Zhang, J. He, and G. Huang, "Online fault detection of permanent magnet demagnetization for IPMSMs by nonsingular fast terminal-sliding-mode observer," Sensors, vol. 14, no. 12, pp. 23119-23136, 2014.

[23] S. Abourida and J. Belanger, "Real-time platform for the control prototyping and simulation of power electronics and motor drives," in Proceedings of the 3rd International Conference on Modeling, Simulation, and Applied Optimization, pp. 1-6, Shariah, UEA, January 2009. 


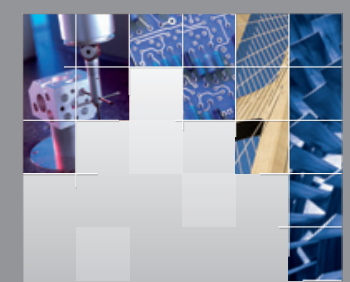

\section{Enfincering}
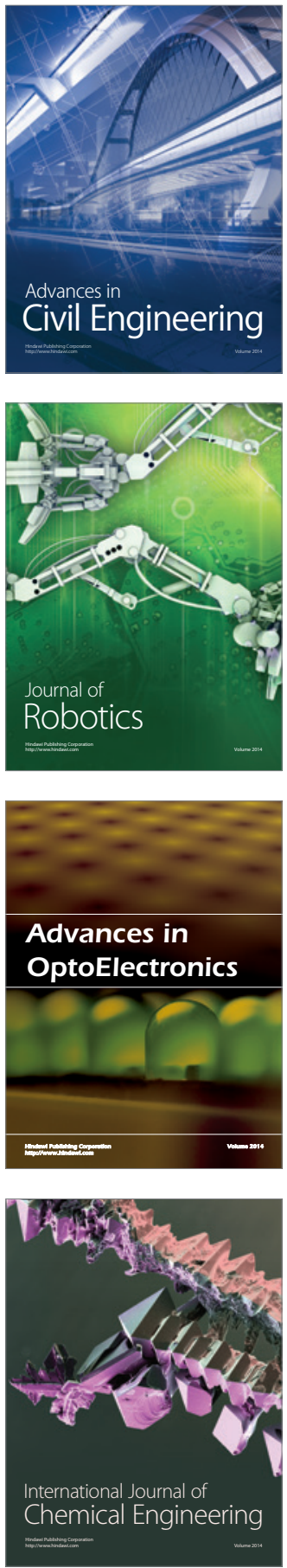

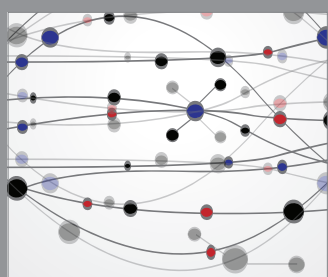

The Scientific World Journal

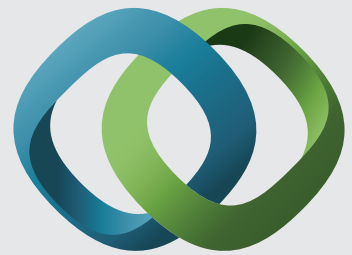

\section{Hindawi}

Submit your manuscripts at

https://www.hindawi.com
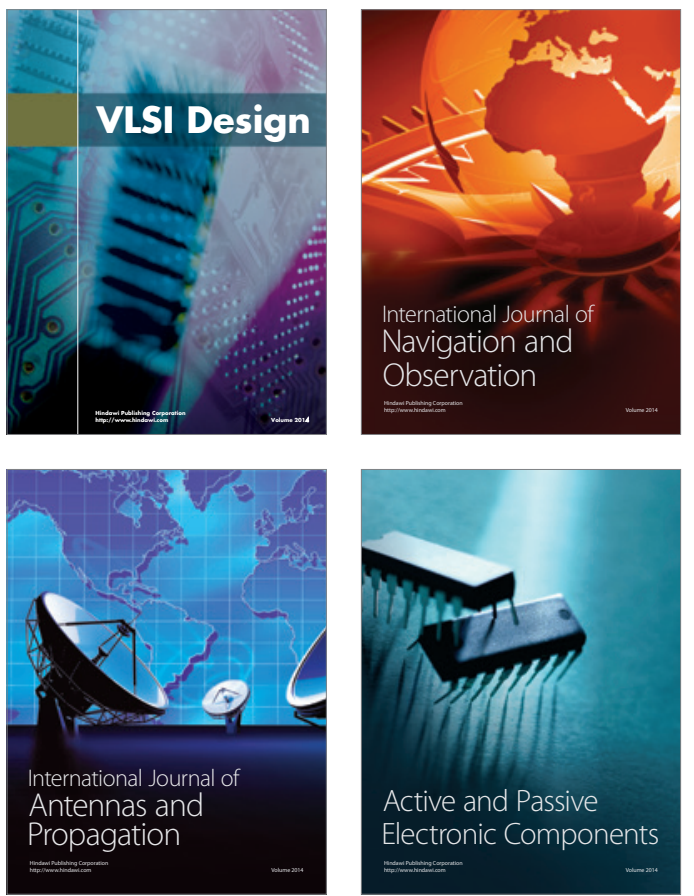
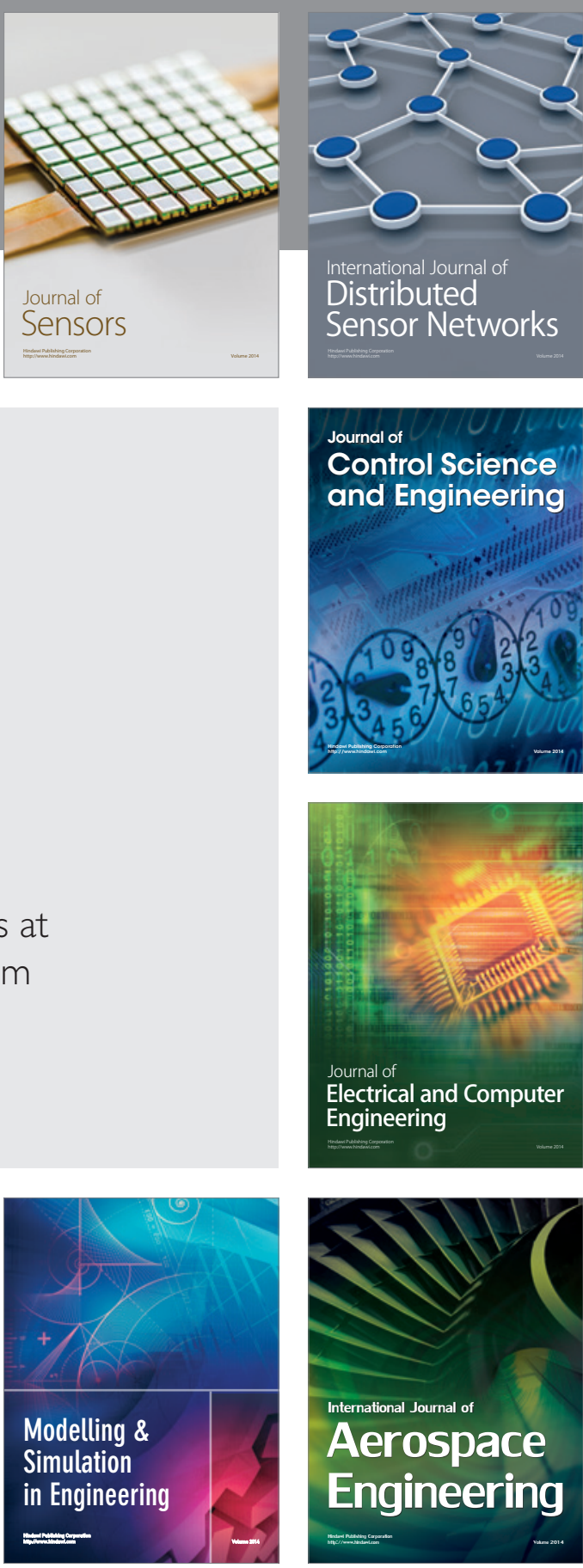

International Journal of

Distributed

Sensor Networks

$-$

Joumal of

Control Science

and Engineering
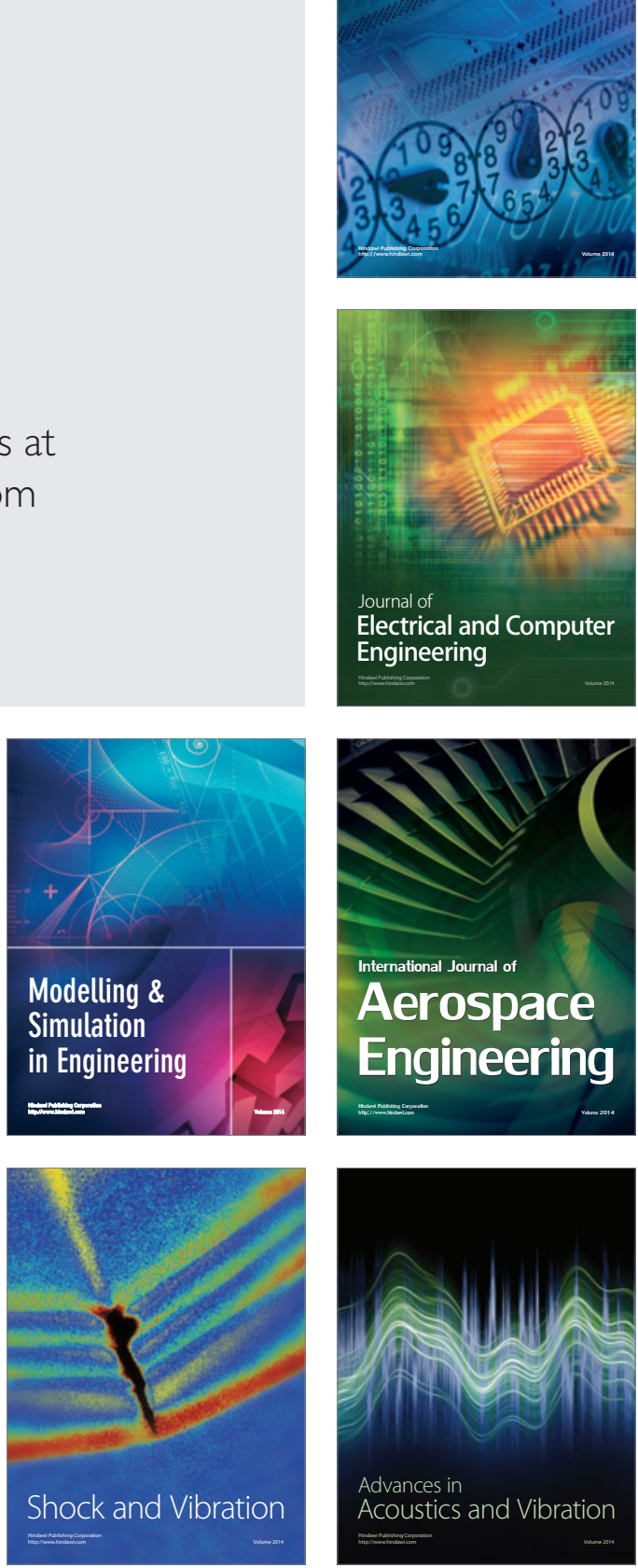